\title{
Preschool weights and heights of Europeans and five subgroups of Asians in Britain
}

\author{
A R Gatrad, N Birch, $M$ Hughes
}

\begin{abstract}
Heights and weights of five subgroups of Asian (545) and European children (685) were recorded after birth, at 1 year, 2 years, and at 5 years. Asian children were divided into Muslim Gujarati, Muslim Pakistani, Muslim Bangladeshi, Hindu, and Sikh. Although the Europeans were significantly the heaviest at birth (3.42 $\mathrm{kg}$ boys and $3.26 \mathrm{~kg}$ girls) when compared with any of the other groups, it was the Sikhs who had the best weight gain. They were also the heaviest at 5 years when compared with other groups, including the Europeans $(20.13 \mathrm{~kg}$ and $19.22 \mathrm{~kg}$ for Sikh boys and girls respectively compared with $18.83 \mathrm{~kg}$ and $18.42 \mathrm{~kg}$ for European boys and girls respectively). Hindus had the lightest birth weight. Their weight at 5 years $(17.41 \mathrm{~kg}$ boys and $16.93 \mathrm{~kg}$ girls $)$ and that of the Muslim Gujaratis $(17.27 \mathrm{~kg}$ boys and $17 \cdot 20 \mathrm{~kg}$ girls) was comparable and was lowest, whereas that of the Bangladeshis at this age was the greatest among the Muslims (18.56 kg for boys and $17 \cdot 87 \mathrm{~kg}$ for girls).

Sikh boys and girls were found to be the tallest of all the groups, including the Europeans, at all periods of measurements - including at 5 years when the Sikh boys and girls were $3 \mathrm{~cm}$ and $1.5 \mathrm{~cm}$ taller than the European boys and girls. Hindus were the shortest of all the groups throughout the period of study.

(Arch Dis Child 1994; 71: 207-210)
\end{abstract}

Asian babies at birth are, on average, lighter than Europeans. ${ }^{1}$ Although some previous studies have divided the Asian group geographically into Indians and Pakistanis, ${ }^{2}$ others have divided it in terms of religion into Hindu, Sikh, and Muslim ${ }^{3}$; however, some have not divided this group at all. ${ }^{4}$ In the present study the Muslim group was divided into Gujaratis, Pakistanis, and Bangladeshis, as geographically and culturally there are some differences between the Muslim subgroups, for example, Muslim Gujaratis are nonvegetarians from India and Bangladeshis are non-vegetarians from the area formerly called East Pakistan to the north east of India. Thus geographical, cultural, and religious considerations were taken into account in this study. The addition of Sikhs and Hindus to the Muslim group formed the Asian group, which was defined as brown skinned people whose parents or grandparents originated from India, Pakistan, or Bangladesh.
There is currently a lack of published studies comparing the growth of these children in the first few years of life. Such a study is particularly important as there is a widespread belief among paediatricians that the growth of the Asian child is generally not as good as that of the European. During the course of research it was encouraging to note from one study that measurements taken by health visitors were sufficiently accurate for practical purposes in following up growth of children. ${ }^{5}$ The aim of our study was to study prospectively and compare (a) the weights of these children from birth to 5 years of age and (b) the lengths of these children from birth to 5 years of age. Growth of boys and girls were studied separately.

\section{Subjects and methods}

Asian mothers and their babies were divided at birth into five subgroups as stated above. The labour ward was made aware of the study to ensure accurate records of birth weight (within $10 \mathrm{~g}$ ) were kept. Only live singleton births to non-diabetic mothers were included and any child with a congenital abnormality excluded. Every third European baby and all Asian babies born over a period of 17 months (January 1985 to June 1986) and who satisfied the criteria were included in the study. The ethnic subgroup of the mother was recorded accurately postnatally, and where there was an occasional doubt, the mother was interviewed in her own language. Information on country of birth of mother was also obtained. The heights and weights of babies were recorded at regular intervals after birth: at 1 year, 2 years, and the first (preschool) school medical examination. As length measurement in the labour ward is often hurried and possibly inaccurate, the first measurement was taken at 6 weeks. All community child health clinics in Walsall were made aware of this research and instructed to measure within $0.5 \mathrm{~cm}$ and $10 \mathrm{~g}$ accuracy. Health visitors were shown how to measure height accurately. The study continued to the end of 1992 to ensure that most of the children in the study had their preschool medical examination. The heights and weights at 1 and 2 years were taken within three weeks of the expected time and those at 6 weeks within seven days. As not all schools carried out the preschool medical examination uniformly, there was a spread of ages (4.8 to $7 \cdot 3$ years) for the measurements. In view of this a regression equation was formulated using the data for each group and an estimate of height and weight at 5 years, the legal school entry age, was calculated. 
Table 1 Boys' and girls' weight ( $\mathrm{kg}$ )

\begin{tabular}{lrrrrrr}
\hline & No & Birth & 1 year & 2 years & 5 years $(\text { No })^{*}$ \\
\hline Boys & & & & & \\
$\quad$ European & 362 & 3.42 & 10.32 & 12.47 & $18.83(359)$ \\
$\quad \begin{array}{l}\text { Muslim } \\
\text { Gujarati }\end{array}$ & 18 & 3.06 & 9.52 & 11.75 & $17.27(18)$ \\
$\quad$ Pakistani & 95 & 3.20 & 9.99 & 12.17 & $17.80(86)$ \\
$\quad$ Bangladeshi & 36 & 3.13 & 9.61 & 11.81 & $18.56(36)$ \\
Hindu & 41 & 2.97 & 9.74 & 11.81 & $17.41(39)$ \\
$\quad$ Sikh & 88 & 3.17 & 10.46 & 12.83 & $20.13(78)$ \\
Pooled SD & & 0.54 & 1.02 & 1.15 & 8.67 \\
Girls & & & & & \\
$\quad$ European & 323 & 3.26 & 9.69 & 11.79 & $18.42(323)$ \\
$\quad$ Muslim & & & & & \\
$\quad$ Gujarati & 18 & 2.99 & 9.51 & 11.60 & $17.20(16)$ \\
$\quad$ Pakistani & 86 & 3.05 & 9.46 & 11.65 & $17.52(86)$ \\
$\quad$ Bangladeshi & 46 & 3.10 & 9.44 & 11.57 & $17.87(43)$ \\
$\quad$ Hindu & 38 & 2.83 & 9.31 & 11.49 & $16.93(38)$ \\
$\quad$ Sikh & 79 & 3.09 & 9.52 & 11.83 & $19.21(77)$ \\
$\quad$ Pooled SD & & 0.48 & 0.90 & 1.12 & 8.14 \\
\hline
\end{tabular}

*See text (results) for explanation.

Having collected the data, simple tables of means with pooled standard deviations were constructed in order to compare heights and weights of boys and girls at various ages in all the groups in the study. Significance tests are not shown as they are liable to be misleading as the data are longitudinal and differences in different columns in the tables are not independent.

\section{Results}

Altogether 4102 children were born at the Manor Hospital, Walsall, during the study period, of which $86 \%$ were Europeans, $13 \%$ Asians, and $1 \%$ others. Five hundred and forty five Asian and 685 European babies satisfied the criteria, that is approximately $30 \%$ of all babies (1230) over the 17 month period. There were $640(52 \%)$ boys and $590(48 \%)$ girls included in the study. In the tables, the figures in brackets represent the number of children who could be traced at the preschool medical examination as, when this last measurement was taken, there were some missing data due to families moving away from the area or returning to their homelands. Thus the final number for analysis had altered a little from the data at $0-2$ years. The missing data, however, only account for $2 \%$ of the original sample. Of the 545 Asian mothers,

Table 2 Boys' and girls' height (cm)

\begin{tabular}{|c|c|c|c|c|c|}
\hline & No & 6 weeks & 1 year & 2 years & 5 years $(\mathrm{No})^{*}$ \\
\hline \multicolumn{6}{|l|}{ Boys } \\
\hline $\begin{array}{l}\text { European } \\
\text { Muslim }\end{array}$ & 362 & $56 \cdot 9$ & $75 \cdot 9$ & $87 \cdot 0$ & $108 \cdot 8(359)$ \\
\hline Gujarati & 18 & $56 \cdot 7$ & $75 \cdot 4$ & $86 \cdot 3$ & $109 \cdot 2(18)$ \\
\hline Pakistani & 95 & $56 \cdot 6$ & $75 \cdot 6$ & $86 \cdot 6$ & $108.8(86)$ \\
\hline Bangladeshi & 36 & $56 \cdot 3$ & $74 \cdot 9$ & 85.9 & $108.5(36)$ \\
\hline Hindu & 41 & $55 \cdot 9$ & $74 \cdot 8$ & $85 \cdot 9$ & $108 \cdot 3(39)$ \\
\hline Sikh & 88 & $57 \cdot 2$ & $76 \cdot 4$ & $87 \cdot 6$ & $111.8(78)$ \\
\hline Pooled SD & & $1 \cdot 76$ & $2 \cdot 06$ & $2 \cdot 39$ & $8 \cdot 67$ \\
\hline \multicolumn{6}{|l|}{ Girls } \\
\hline European & 323 & $55 \cdot 9$ & $74 \cdot 8$ & $85 \cdot 7$ & $108 \cdot 3(323)$ \\
\hline $\begin{array}{l}\text { Muslum } \\
\text { Gujarati }\end{array}$ & 18 & $55 \cdot 8$ & $74 \cdot 7$ & $85 \cdot 7$ & $107 \cdot 7(16)$ \\
\hline Pakistani & 86 & $56 \cdot 0$ & $74 \cdot 8$ & $85 \cdot 8$ & $108 \cdot 0(86)$ \\
\hline Bangladeshi & 46 & $56 \cdot 1$ & $74 \cdot 4$ & $85 \cdot 2$ & $108 \cdot 0(43)$ \\
\hline Hindu & 38 & $55 \cdot 6$ & $74 \cdot 2$ & $85 \cdot 1$ & $107 \cdot 3(38)$ \\
\hline Sikh & 79 & $56 \cdot 1$ & $75 \cdot 0$ & $86 \cdot 0$ & $109 \cdot 8(77)$ \\
\hline Pooled SD & & $2 \cdot 04$ & $1 \cdot 87$ & $2 \cdot 17$ & $8 \cdot 15$ \\
\hline
\end{tabular}

${ }^{\star}$ See text (results) for explanation.
$135(24 \cdot 7 \%)$ were born in the UK: nine Muslim Gujaratis (that is $25.0 \%$ of total Muslim Gujaratis), 39 Muslim Pakistanis (21.5\%), 23 Muslim Bangladeshis (28.0\%), 26 Hindus $(32 \cdot 9 \%)$, and 38 Sikhs $(22 \cdot 7 \%)$.

BOYS' WEIGHT ANALYSIS (TABLE 1)

European babies were the heaviest group at birth and Hindus were the lightest. By 1 year the Sikhs have overtaken the European group in mean weight. The Hindus are no longer the lightest as they have overtaken both the Muslim Bangladeshi and Muslim Gujarati groups. The Muslim Pakistani group was heavier than the Muslim Bangladeshi group, and Muslim Gujaratis were the lightest. By 2 years the Sikhs were still heavier than all the groups including the Europeans who remained heavier than the rest. As at 1 year the Muslim Gujarati group remained the lightest. At 5 years Sikhs were still the heaviest with Muslim Bangladeshis and Europeans having similar weights. Additionally the Europeans were much heavier than the Hindus.

\section{GIRLS' WEIGHT ANALYSIS (TABLE 1)}

As with the boys, the heaviest group at birth was the Europeans and the lightest the Hindus. The differences in mean weights between the groups of girls is much less at the 1 year assessment than at birth. Between 1 and 2 years the Sikh girls have gained the most weight and at 2 years are, on average, the heaviest group. At 5 years the Sikh girls were the heaviest and the Hindus the lightest with the Muslim Pakistani and Muslim Bangladeshi groups having intermediate measurements that were very similar.

\section{BOYS' HEIGHT ANALYSIS (TABLE 2)}

The Sikhs were the tallest and Hindus the shortest group at birth but overall the differences between the groups were small. At 1 year the Europeans and Muslim Pakistani groups were both taller than Muslim Bangladeshis. At 2 years the average height of the smallest group, the Hindus, was similar to the Muslim Bangladeshi group. At 5 years as with all previous measurements the Sikhs were the tallest and the Hindus the shortest, although with the exception of the former the measurements were not that dissimilar between the groups.

GIRLS' HEIGHT ANALYSIS (TABLE 2)

Sikh girls were the tallest at all ages. At the 6 week, 1 year, and 2 year measurements, the Hindus and the Bangladeshis were the shortest, but all the groups with the exception of the Sikhs at 5 years had similar heights. It can be seen from the above that:

(a) European boys and girls were heavier than any other single group at birth.

(b) Hindu boys and girls were the lightest group at birth - the boys showing a subsequent good weight gain that was not sustained. 
Table 3 Comparison of birth weights in the study of Clarson et al (1982)2 and the present study

\begin{tabular}{llr}
\hline & Mean $(S D)(\mathrm{kg})$ & No \\
\hline Clarson et al (1968) & & \\
$\quad$ Pakistani & $3.02(0.44)$ & 152 \\
$\quad$ Indian & $2.91(0.49)$ & 106 \\
Clarson et al (1978) & $3.16(0.52)$ & 228 \\
$\quad$ Pakistani & $2.93(0.51)$ & 70 \\
$\quad$ Indian & $3.12(0.51)$ & 263 \\
Present study (1986) & $3.02(0.48)$ & 282 \\
$\quad$ Pakistani & Indian & \\
\hline
\end{tabular}

(c) Sikh and European boys and girls remained heavier at 1 year and 2 year assessments compared with each of the other groups.

(d) The Sikh trend of rapid growth continued to 5 years of age by which time boys and girls were heavier than all other groups including the European boys and girls.

(e) The Muslim boys and girls were heavier than Hindu boys and girls at birth and at 5 years (except Muslim Gujarati boys at 5 years)

(f) The Muslim Gujarati boys and girls were the lightest of the Muslim group at 5 years.

(g) Muslim Bangladeshi boys and girls had rapid growth particularly after the second year. In the first two years their growth was comparable with the Hindus and the Muslim Gujaratis.

(h) As expected boys were heavier than girls in all groups throughout the period of study.

(i) The Sikh boys and girls were the tallest at birth and remained so till the age of 5 years. For the Hindus the reverse was true.

\section{Discussion}

To the initiated, Asians are not a homogeneous group as they can be clearly distinguished by name, physical characteristics, dress, and even colour.

The present study highlights the fact that growth is unexpectedly better in the Sikh children, a fact that would not be clear if Sikhs were included in a combined Indian group as in previous studies. As a result of not breaking down the Asian group into subunits, as done in the present study, the authors in the Clarson et al study had some conflicting observations. ${ }^{2}$ The mean weight of Pakistani and Indian babies in their study in Birmingham was 3.02 $\mathrm{kg}$ and $2.91 \mathrm{~kg}$ respectively in 1968 ; and $3 \cdot 16$ $\mathrm{kg}$ and $2.93 \mathrm{~kg}$ respectively in 1978 (table 3 ). Our study, which had large numbers, is comparable in geographical terms (as Walsall is only 10 miles from Birmingham) and confirms that the Pakistani and the Indian babies (Hindus, Sikhs, and Muslim Gujaratis) in $1985 / 86$ were heavier $(3.12 \mathrm{~kg}$ and $3.02 \mathrm{~kg}$ respectively) than in 1968 , but the average weight of the Pakistanis in the present study was slightly less than observed in 1978. Thus the Indian group continued to increase in weight from 1968-86, but the Pakistani group only increased in weight from 1968-78 (Clarson et al) but there was a slight decrease from 1978 (Clarson et al) to 1986 (present study). A possible explanation for this is that in the study of Clarson et al Pakistanis exceeded Bangladeshis by a factor of eight; in our study this factor was only two. We have already demonstrated that the Muslim Pakistani weight exceeds the Muslim Bangladeshi weight, and assuming this difference in birth weight was similar in 1968 and 1978, then the greater number of Pakistanis in the Clarson et al study would give a higher mean birth weight for the combined group. The increased proportion of Muslim Bangladeshis in our study would have the opposite effect. Unfortunately, unlike the present study, there was no inclusion of the birth weight of European children in their study.

Statistical analysis of the results of birth weights from both studies (table 3 ) show that there is a significant increase $(p<0.05)$ in birth weight for both Indian and Pakistani babies between the period 1968 (Clarson et al) to 1986 (present study). However, no significant differences were observed in the birth weights between 1978 (Clarson et al) and in 1986.

Muslim Gujaratis, otherwise known as 'Surtees', and the Hindus were the lightest at birth. In this context, it would be of interest to note that the Muslim Gujaratis come from parts of India where there is a large concentration of Hindus, for example, Gujarat. Furthermore, although religions are different, the language spoken by the two groups is Gujarati. The inclusion of Muslim Gujaratis in the Indian group because they come from India, or into the Muslim group because of their religion, could quite significantly affect the analytical outcome. In England, Gujaratis are concentrated in places such as Bolton, Blackburn, and Dewsbury, and Hindus in places such as Leicester and Harrow. It is usually the Muslim Gujarati or a Hindu parent that presents to a paediatrician with the complaint that his child is not eating enough and not growing adequately.

Growth is determined by genetic, environmental, and nutritional factors. Differences in birth weight could be attributed to maternal diet, for example Hindu mothers being vegetarian had the lightest babies. In this study approximately $60 \%$ of Hindus and $25 \%$ of Sikh mothers were vegetarians. A much smaller percentage of their children, however, were vegetarians $(26 \%$ and $11 \%$ respectively). The fact that Sikhs are the most affluent of the Asian groups in Walsall, and as a result have a more wholesome diet, may have a positive effect on the nutrition of their children, especially at a young age, resulting in improved growth. A similar effect may be seen with the Bangladeshis, as a high proportion of this group work in the food industry such as restaurants, etc.

It has been reported that Japanese nationals who emigrated to the US tended to increase in size until they were similar to their native American counterparts. ${ }^{6}$ A similar situation appears to be occurring among Asian children born in the UK to parents and grandparents who originally came here nearly 30 years ago. Although the European children at birth in our 
study were significantly heavier than any other group, it is possible that in future the weights of Asian children may not be that different from the Europeans.

Height among Asian children is unexpectedly greater than is thought to be the case by most paediatricians. Of particular interest was the fact that Sikh boys and girls were taller than the Europeans at around 5 years (boys significantly so) and appear to be taller at all other measurements taken before this. Hindu boys and girls were the shortest of all groups at all periods with the Muslim groups having a height measurement in between them and the Sikhs.

Anecdotally, paediatricians have believed the growth of Asian children to be a centile below the Europeans on the standard Tanner and Whitehouse charts. This generalisation is not tenable in the light of the present study. It would, however, be extremely interesting to analyse the growth of the children in our study through puberty to adulthood, but it is likely that contact would be lost with many of the subjects.

1 Arthurton MW. Immigrant children and the day to day work of a paediatrician. Arch Dis Child 1972; 47: 126-30.

2 Clarson CL, Barker MJ, Marshall T, Wharton BA. Secular changes in birth weight of Asian babies born in Birmingham. Arch Dis Child 1982; 57: 867-71.

3 Chetcuti P, Sinha SH, Levene MI. Birth size in Indian ethnic subgroups born in Britain. Arch Dis Child 1985; 60: 868-70.

4 Alvear J, Brooke OG. Fetal growth in different racial groups. Arch Dis Child 1978; 53: 27-32.

5 Ahmed ML, Yudkin PL, Macfarlane JA, et al. Are measurements of height made by health visitors sufficiently accurate for routine screening of growth? Arch Dis Child 1990; 65: 1345-8.

6 Greulich WW. Some secular changes in the growth of American and native Japanese children. Am $\mathcal{f}$ Phys Anthropol 1976; 45: 553-68. 